\title{
A 3-Year Study of Resident Reaction to 2011 ACGME Work Hour Rules in a Family Medicine Residency
}

Anne Picciano, MD | Lauren Guth, PsyD, MEd I Robin O. Winter, MD, MMM

PRiMER. 2018;2:12.

Published: 7/16/2018 | DOI: 10.22454/PRiMER.2018.915876

\section{Abstract}

Introduction: 2011 Accreditation Council for Graduate Medical Education (ACGME) work hour rules prompted concerns regarding potential negative impacts on patient care and resident education. We were interested in resident reaction to call restructuring and night float (NF) in a family medicine residency over 3 years following implementation of the 2011 rules.

Methods: We conducted structured interviews of residents from 2011-2012 through 2013-2014. Interviews were recorded, transcribed, and analyzed for themes.

Results: Fifty-eight interviews were conducted, including 18/18 residents in 2011-2012 (100\%), 18/20 residents in 2012-2013 (90\%), and 22/22 residents in 2013-2014 (100\%). Following introduction of the 24-hour work limit, upper year residents reported significantly less fatigue and improved personal lives, patient care, and educational experience. Reactions to NF varied with length and intensity of the NF rotation; most PGY-1 residents reported increased fatigue, more burnout, and worse personal lives on NF. Most residents felt patient care quality on NF did not differ from non-NF rotations because improved inpatient nighttime continuity mitigated effects of fatigue and increased care transitions. Reactions regarding educational experience on NF were initially negative, but improved over time.

Conclusions: Residents' reactions to 2011 ACGME work hour rules suggest the rules improved resident wellbeing, except on NF. Negative effects of NF may be minimized by limiting NF rotations to 5 nights/week for 2 consecutive weeks, and 1 month total per academic year.

\section{Introduction}

The Accreditation Council for Graduate Medical Education (ACGME) issued duty hour regulations in 2003 limiting residents to an 80-hour work week and 30-hour shifts. ${ }^{1}$ In 2011, updated rules limited interns to 16 -hour shifts and prohibited outpatient clinics after 24 hours of duty. Goals of both reforms included improved patient safety and resident well-being. ${ }^{2}$ After reviewing studies evaluating 2011 changes, the ACGME sanctioned 24-hour shifts for interns in 2017. ${ }^{3}$

Attempts to assess effects of the 2011 regulations have yielded variable results. One systematic review found no overall improvement in patient care or resident well-being, and negative educational impacts. ${ }^{4}$ Another stressed significant limitations of current studies. ${ }^{5}$ As stakeholders in this debate, residents may provide valuable feedback. Our review of studies assessing residents' perceptions $\mathrm{s}^{6-21}$ found that most identified improved resident well-being, worsened education, and unchanged patient care. Almost all used only surveys to obtain resident input. Most studied only general surgery, $6,17,20$ internal medicine $e^{8,9,10,19,21}$ or pediatric ${ }^{14,15,18}$ residents. None report resident perspectives beyond a 1 -year period under the new rules. 
Given the lack of studies of family medicine residents, whose training differs significantly from other specialties, we were interested in resident reactions to changes implemented in our residency to comply with 2011 regulations. Changes included residents no longer having office hours or rotation responsibilities after a night on call, and the introduction of night float (NF) rotations. We chose semistructured interviews over a 3-year period to obtain meaningful resident feedback that could inform curricular decisions.

\section{Methods}

We conducted this study over 3 academic years (2012-2014) at the JFK Family Medicine Residency Program, a community hospital-based program in New Jersey. The program expanded from 18 to 22 residents over the 3 years. Structural changes, including iterations of NF, are summarized in Table 1.

An interview script (Table 2) was developed to prompt input on areas of interest identified in the literature, as well as open-ended feedback. All residents were invited to participate by study author AP at morning reports in June each year. One-on-one interviews were conducted in the Family Medicine Center by authors AP and LG (both clinical faculty at the program) at times convenient to each resident in June/July 2012, 2013, and 2014. Informed consent was obtained.

Interviews were recorded and transcribed verbatim. Authors AP and LG independently coded each transcript. Discrepancies in themes between investigators were resolved through discussion until consensus was reached. Saturation was reached after $50 \%-60 \%$ of interviews each year. Reflexivity was employed by having investigators with different backgrounds (1 physician [AP], 1 psychologist [LG]) code independently, then challenge each other's preconceptions during analysis. We did not use qualitative analysis software in data analysis. Quote samples chosen were either most descriptive of a common theme or an unusual perspective. Study approval was obtained through the JFK Medical Center Institutional Review Board.

\section{Results}

Fifty-eight interviews were conducted (18/18 residents [100\%] in 2012, 18/20 residents [90\%] in 2013, and 22/22 residents [100\%] in 2014). Interviews ranged from 15 to 75 minutes. Table 3 shows demographic data of participants. Table 4 provides quote samples.

\section{Twenty-Four-Hour Duty Limit for Senior Residents}

\section{Marked Improvement in Fatigue Had Diverse Positive Impacts}

All senior residents in 2012 reported significantly decreased fatigue, saying going home postcall provided essential recovery time for their physical and emotional well-being. Personal lives improved because of more time for family/friends, sleep, exercise, chores, and relaxation. Residents who expressed feelings of burnout felt these lessened due to less fatigue and more time away from work.

Most residents also felt patient care improved because being better-rested made them less irritable and better able to focus, listen, and establish rapport with patients, and less prone to making mistakes. Some reported spending more time with patients on call rather than trying to maximize their own sleep time. Residents also felt the decrease in fatigue created a better educational experience, with more time and energy to study and enhanced receptivity to learning. Some mentioned a slight decrease in clinical experience but felt the benefits more than compensated.

\section{Night Float}

\section{Increased Fatigue is Nearly Universal on NF Rotations Longer Than 2 Weeks}

Residents who experienced 4-8 weeks of NF in a year reported more fatigue on NF due to difficulty shifting sleep schedules, lack of sunlight exposure, long shifts, and less social interaction. Fatigue was cumulative, really hitting by the third week; many residents suggested limiting NF to 2 weeks. All residents who experienced both 5- and 6-nights/week NF noted less fatigue with 5 nights/week. Reasons for NF fatigue remained constant throughout the 
3 years among PGY-1 and PGY-2 residents. Most PGY-3 residents on 2-week NF did not feel a difference in fatigue compared with other rotations.

\section{Fatigue and Social Isolation Were Main Contributors to Burnout and Worse Personal Lives on NF}

Most residents experiencing 6-8 weeks of NF in a year felt more burnout on NF, mainly due to fatigue and social isolation. Being too tired to interact with others even on time off increased social isolation, which in turn worsened fatigue. Residents described fewer colleagues or staff to interact with on nights and feeling excluded from the larger residency group. Fatigue, irritability, and being on different schedules from others negatively affected personal relationships and self-care. Most residents experiencing only 4 weeks (PGY-2) or 2 weeks (PGY-3) of NF in a year felt no difference in burnout on NF vs non-NF rotations.

\section{Educational Impact of NF, Initially Negative, Trended Toward Neutral/Positive Over 3 Years}

Most PGY-1 residents in 2012 felt NF negatively affected education because fatigue interfered with reading and receptivity to learning, and there were fewer attending physician interactions. Benefits of independent decisionmaking, senior resident teaching, and unique nighttime clinical scenarios were mentioned by only one resident in 2012, but became common themes in 2013 and 2014 among PGY-1s. They increasingly reported that NF experiential learning developed clinical reasoning and independence. Senior residents on NF shared this more positive perspective, citing fatigue as interfering with learning less often, and noting the educational value of teaching junior residents. Only a few residents lamented missing daytime lectures; senior residents believed missed didactics had minimal impact.

Overall, residents felt patient care quality and safety on NF was comparable to non-NF rotations because fatigue and increased care transitions were balanced by improved nighttime continuity. Residents felt a consistent resident on duty each night resulted in greater patient ownership, leading to better clinical decision-making than occurred with traditional call.

\section{Discussion}

Resident reaction to curricular restructuring triggered by 2011 ACGME work hour regulations is one measure of the rules' effectiveness. Reactions of residents in our study working under 2003 and 2011 rules confirm others' findings of improved resident well-being with 2011 limits. Our residents experiencing both sets of rules expressed more positive perceptions of the 2011 rules' impact on education and patient care than found in many other studies. This may reflect effects of greater fatigue reduction as a result of abolishing postcall office hours in a family medicine residency compared with more inpatient-focused specialties.

While 2017 rules allowing interns to work 24-hour shifts may decrease the necessity of NF, likely many residencies will continue to use this option. Our findings suggest NF should ideally be limited to 5 nights/week, 2 weeks in duration and 4 weeks total per academic year to minimize negative effects on resident well-being. The theme of social isolation on NF highlights a need to increase social supports during NF rotations.

Our residents' negative opinions about the educational impact of NF in 2012 were consistent with the literature, but an evolution toward more positive views over the following 2 years has not previously been reported. This finding may relate to changing NF from 6 to 5 nights/week, and introducing some shorter NF and senior NF (pairing a consistent senior and PGY-1 resident). It is also possible residents in the latter part of the study may have viewed the NF learning experience more positively simply because it was their only opportunity to experience the unique nocturnal clinical scenarios and independence previously available with traditional call.

Improved inpatient continuity on NF emerged as a strong theme in our study. The idea of a night resident team more familiar and actively engaged with patients in a manner that positively affects patient care is a benefit of NF that study investigators did not anticipate.

Our study is limited by having been conducted in a single family medicine residency and is only a report of residents' perceptions, with no objective outcome measures. Interviewers were clinical faculty at the residency, which may 
have influenced resident responses; however, residents were reassured that participation was voluntary, having no impact on academic standing, and responses would be kept confidential and anonymous during transcription.

\section{Conclusions}

This 3-year study of residents' reactions to the 2011 ACGME work hour rules suggests the rules improved resident quality of life, except on NF, without negatively impacting education or patient care. Negative effects of NF rotations may be mitigated by limiting them to 5 nights/week for 2 consecutive weeks, and 4 weeks total in an academic year.

\section{Tables and Figures}

Table 1: Call and Night Float (NF) Structure

\begin{tabular}{|c|c|c|c|c|}
\hline & Prior to 2011 & $2011-12$ & $2012-13$ & $2013-14$ \\
\hline PGY-1 & $\begin{array}{l}24 \text {-hour call } \\
+6 \text { hours after }\end{array}$ & $\begin{array}{c}2 \text { NF rotations } \\
\text { (4 weeks each, } \\
6 \text { nights/week) } \\
\text { 12-hour weekend shifts }\end{array}$ & $\begin{array}{c}2 \text { NF rotations } \\
\text { (4 weeks each, } \\
5 \text { nights/week) } \\
\text { 12-hour weekend shifts }\end{array}$ & $\begin{array}{c}2 \text { NF rotations } \\
\text { (4 weeks and } 2 \text { weeks, } \\
5 \text { nights/week) } \\
\text { 12-hour weekend shifts }\end{array}$ \\
\hline PGY-2 & $\begin{array}{l}24 \text {-hour call } \\
+6 \text { hours after* }\end{array}$ & $\begin{array}{l}\text { 24-hour call } \\
\text { Day off postcall }\end{array}$ & $\begin{array}{c}\text { 24-hour call } \\
\text { Day off postcall }\end{array}$ & $\begin{array}{c}1 \mathrm{NF} \text { rotation (4 weeks, } 5 \\
\text { nights/week) } \\
\text { 24-hour weekend shifts }\end{array}$ \\
\hline PGY-3 & $\begin{array}{c}\text { 24-hour call } \\
+6 \text { hours after* }\end{array}$ & $\begin{array}{l}\text { 24-hour call } \\
\text { Day off postcall }\end{array}$ & $\begin{array}{l}\text { 24-hour call } \\
\text { Day off postcall }\end{array}$ & $\begin{array}{c}1 \mathrm{NF} \text { rotation (2 weeks, } 5 \\
\text { nights/week) } \\
\text { 24-hour weekend shifts }\end{array}$ \\
\hline \multirow[t]{2}{*}{$\begin{array}{c}\text { Number } \\
\text { of } \\
\text { residents }\end{array}$} & $6-6-6$ & $6-6-6$ & $8-6-6$ & $8-8-6$ \\
\hline & $\begin{array}{c}\text { * Usually office } \\
\text { hours }\end{array}$ & \multicolumn{3}{|c|}{ No office hours during NF } \\
\hline
\end{tabular}




\section{Table 2: Interview Script}

We are interested in understanding the impact on residents of the newest ACGME work hour rules that took effect in July 2011. In our program, this meant residents no longer had office hours or rotation responsibilities after a night of call and that night float rotations were added to the residency program.

We will be asking you a series of questions about your work experience over the past year.Please answer as honestly as you can.

We would like you to try to compare your experience in the past academic year with the prior year (for PGY-2 and 3 residents in 2012 and 2013, or when you were on night float rotations vs other rotations [for all PGY-1 residents, and PGY-2 and 3 residents in 2014]):

1. Overall, did you feel a difference in your level of fatigue? Can you explain why (or why not)?

Can you think of any examples?

2. Overall, did you feel your level of burnout (if any) was different? (Burnout defined as feeling emotionally exhausted, depersonalizing patients, and a diminished sense of personal accomplishment)

Can you explain why (or why not)?

Can you think of any examples?

3. Do you think the quality of care patients received from you was different? If so, how? Why do you think this was?

Can you think of any examples?

4. Do you think the safety of patients you were caring for was different? If so, how? Why do you think this was? Can you think of any examples?

5. Do you think your learning/educational experience was different? If so, how? Why do you think this was? Can you think of any examples?

6. Do you think your personal/home/family life was different? If so, how? Why do you think this was? Can you think of any examples?

7. If the choice was yours, and you were just starting residency, would you choose to work under a system that included night float? (vs a 24-hour call system)?

Can you explain further?

8. What other feedback or comments do you have regarding the 2011 duty hour rules?

Table 3: Participant Demographics

\begin{tabular}{|c|c|c|}
\hline Characteristic & Number of Participants & $\%$ \\
\hline \multicolumn{3}{|l|}{ Sex } \\
\hline Male & 14 & 41.2 \\
\hline Female & 20 & 58.8 \\
\hline \multicolumn{3}{|l|}{ Age at First Interview } \\
\hline$\leq 30$ & 19 & 55.9 \\
\hline$>30$ & 15 & 44.1 \\
\hline \multicolumn{3}{|l|}{ Race } \\
\hline Caucasian & 10 & 29.4 \\
\hline African American & 3 & 8.8 \\
\hline Asian & 21 & 61.8 \\
\hline
\end{tabular}


Table 4: Resident Quotations

\begin{tabular}{|c|c|}
\hline Topic & Resident Comments \\
\hline \multirow[t]{2}{*}{$\begin{array}{l}\text { 24-hour } \\
\text { duty limit }\end{array}$} & $\begin{array}{l}\text { Improved fatigue } \\
\text { "We used to have to round and do office after } 24-\text { hour call, so those hours were extremely difficult. Even if you did get } \\
\text { a few hours of sleep during the call, you would still be foggy and dysfunctional the next day. So definitely having a day } \\
\text { to recuperate after the call significantly reduces the fatigue." -PGY-2, } 2012 \\
\text { Improved quality and safety } \\
\text { "There were some times when we would have to be in office the day after [24-hour call], and when you're fatigued, } \\
\text { there were occasions when you'd write the wrong order, or your therapeutic relationship is not as strong as it would be } \\
\text { if you came off a full night's sleep, so I definitely think it affects your ability to work." -PGY-2, academic year } 2012 \\
\text { "It's safer for the residents and for the patients [to go home after } 24-h o u r \text { call]. I used to drive home after } 24-h o u r \\
\text { and drive an hour and that was even dangerous. I was literally falling asleep. You're forcing yourself to stay awake, } \\
\text { trying to drink coffee. So if it affects you that much, I'm sure it's affecting patient safety as well." -PGY-2, 2012 } \\
\text { Improved personal life } \\
\text { "If l'm coming home from a 24-hour call, I still have energy in the day to go to the gym, go out, read a book; you're able } \\
\text { to engage in activities...[before, when you had to work after call,] you didn't have that time for yourself and for your own } \\
\text { mental health." } \\
\text {-PGY-2, } 2012\end{array}$ \\
\hline & $\begin{array}{l}\text { Improved education } \\
\text { "When l'm less fatigued I feel more receptive to learning." -PGY-3, } 2012 \\
\text { "[Not having to work] the six hours [post-call] I get to rest, so after that I can do my reading...[before], when you worked } \\
\text { those extra hours [post-call]...you would go home and just sleep-you probably wouldn't wake up until the next day..."- } \\
\text { PGY-2, } 2012\end{array}$ \\
\hline $\begin{array}{l}\text { Fatigue on } \\
\text { Night Float } \\
(N F)\end{array}$ & $\begin{array}{l}\text { "It's just because your sleep is not continuous... your sleep cycle changes and you wake up from time to time. } \\
\text { During the day, you can't sleep much, and that's the reason why you are more fatigued." -PGY-2, } 2014 \\
\text { "[NF] does take a lot out of you, coming to the last 3rd or } 4 \text { th week because you're sleep deprived and nothing can } \\
\text { make up for } 8 \text { hours of sleep. You see changes after the 3rd or 4th week." -PGY-1, } 2012\end{array}$ \\
\hline $\begin{array}{l}\text { Burnout on } \\
\text { NF }\end{array}$ & $\begin{array}{l}\text { "By the time you reach that 3-4 week, you are just snappy, you're irritable, things that you should be able to tolerate on } \\
\text { a regular basis, you just say "Okay, let's get it done, I don't want to hear anything else." You are more edgy. You are } \\
\text { just grumpy and just want to get to the point because you don't want to waste any more time. You get more burned out } \\
\text { coming toward the end of NF." -PGY-1, } 2012\end{array}$ \\
\hline $\begin{array}{l}\text { Personal } \\
\text { life on NF }\end{array}$ & $\begin{array}{l}\text { "I was unable to socialize normally with my coworkers and residents and unable to just even have my normal evening } \\
\text { ritual that I find very helpful for stress relief-even if it's just reading or watching TV or zoning out at night-time... With } \\
\text { NF, you go home and you try to sleep but you couldn't sleep because it was bright and you try to do stuff. I tried to do } \\
\text { the gym after NF and that helped a little to really exhaust you if you could get some sleep. But it was a challenge." - } \\
\text { PGY-1,2012 } \\
\text { "On NF, you didn't have much of a personal life, especially when doing it for } 6 \text { nights. The } 5 \text { nights did allow you to } \\
\text { have more time to interact with friends and family." -PGY-3, 2014 }\end{array}$ \\
\hline $\begin{array}{l}\text { Educational } \\
\text { value of } \\
\text { NF }\end{array}$ & $\begin{array}{l}\text { PGY-1s: } \\
\text { 2012: } \\
\text { "I think my learning was somewhat inhibited on NF because a lot of the daily activities and daily learning that occurs } \\
\text { during the program ... you basically have no exposure to that at all...I think there's also people less willing to teach } \\
\text { constantly at } 2 \text { am as opposed to when you're on a regular rotation during the day. On NF, you're trying to read on } \\
\text { your own and teach yourself, as opposed to getting the help and it's a little hard to when you're very tired from doing a } \\
\text { month of NF." } \\
2013 \text { : } \\
\text { "There is less time for reading and studying on NF. We missed the Thursday [teaching] seminars... who knows if there's } \\
\text { something in those lectures that could have helped in patient care somehow." } \\
\text { "I personally was too tired to do much studying, but if we saw something different, I would try to look it up then to see } \\
\text { what a plan would be for [the patient], but I don't know how much of that I retained." } \\
\text { 2014: } \\
\text { "I think it's a great learning experience. I think NF is a good thing you do. Like I said, you get more responsibility and } \\
\text { you get to make decisions on your own, rather than asking other people and it makes you confident." } \\
\text { Senior residents: } \\
\text { PGY-3, 2014: } \\
\text { "I felt my learning was probably better on the NF system because I was actually working with the same intern every } \\
\text { night...that helped me learn as a teacher and going back and re-learning stuff myself, so that I could go over it with } \\
\text { him.." } \\
\text { PGY-2, 2014: } \\
\text { "I think you have more time to read [on NF]. I mean, some nights when you're not too busy you have more time to } \\
\text { read. And when you're doing admissions, you're looking things up as well." }\end{array}$ \\
\hline $\begin{array}{l}\text { Patient } \\
\text { care } \\
\text { on NF }\end{array}$ & $\begin{array}{l}\text { "The quality of care] is better on NF. The senior didn't have a grasp of the patients like I did, so I was very familiar with } \\
\text { the patients because I had a month of continuity with the same group of patients." -PGY-1, } 2013 \\
\text { "With the NF system, I was able to provide better care. I felt very comfortable with managing [patients] on NF because } \\
\text { I knew every day what was going on with them. [For example,] a patient had a long CCU stay over a } 2 \text { week period } \\
\text { my first year and I was down there every night, had a relationship with the family, and was able to discuss in detail } \\
\text { prognosis, diagnosis, and what was going on." } \\
\text { "PGY-2, } 2013 \\
\text { "I think senior NF is actually very good because I knew the patients on a night-to-night basis. I knew what was going } \\
\text { on with them all the time. I knew their medical history... as opposed to } 24-h \text { hour call where you have more of an attitude } \\
\text { of "just make sure nothing bad happens overnight to these people you don't really know but if something happens you } \\
\text { put a Band-Aid on it." On senior NF, you feel like you're [part of the team and] continuity of care." -PGY-3, } 2014\end{array}$ \\
\hline
\end{tabular}




\section{Acknowledgments}

The authors acknowledge the JFK Family Medicine residents who participated in this study (classes of 2012, 2013, 2014) and Rebecca Van Ness for her assistance in manuscript preparation.

\section{Corresponding Author}

Anne Picciano, MD

JFK Family Medicine Residency, 65 James St, Edison, NJ 08820. 732-321-7495.

anne.picciano@hackensackmeridian.org

\section{Author Affiliations}

Anne Picciano, MD - JFK Family Medicine Residency, Edison, NJ

Lauren Guth, PsyD, MEd - JFK Family Medicine Residency, Edison, NJ

Robin O. Winter, MD, MMM - JFK Medical Center, Edison, NJ

\section{References}

1. Philibert I, Friedmann P, Williams WT; ACGME Work Group on Resident Duty Hours. Accreditation Council for Graduate Medical Education. New requirements for resident duty hours. JAMA. 2002;288(9):1112-1114. https://doi.org/10.1001/jama.288.9.1112

2. Accreditation Council for Graduate Medical Education. History of Duty Hours. http://www.acgme.org/WhatWe-Do/Accreditation/Clinical-Experience-and-Education-formerly-Duty-Hours/History-of-Duty-Hours. Accessed June 14, 2018.

3. Burchiel K, Zetterman R, Ludmerer K, et al. The 2017 ACGME Common Work Hour Standards: promoting physician learning and professional development in a safe, humane environment.

4. Bolster $L$, Rourke $L$. The effect of restricting residents' duty hours on patient safety, resident well-being and resident education: an updated systematic review. J Grad Med Educ. 2015;7(3):349-363. https://doi.org /10.4300/JGME-D-14-00612.1

5. Weiss $P$, Kryger M, Knauert M. Impact of extended duty hours on medical trainees. Sleep Health. 2016;2(4):309-315. https://doi.org/10.1016/j.sleh.2016.08.003

6. Bilimoria KY, Chung JW, Hedges LV, et al. National cluster-randomized trial of duty-hour flexibility in surgical training. N Engl J Med. 2016;374(8):713-727. https://doi.org/10.1056/NEJMoa1515724

7. Allen-Dicker J, Herzig SJ, Mukamal KJ, Tess A. ACGME duty hour revisions and self-reported intern ICU sleep schedules. J Grad Med Educ. 2014;6(3):561-566. https://doi.org/10.4300/JGME-D-13-00263.1

8. Sabri N, Sun NZ, Cummings BA, Jayaraman D. The perceived effect of duty hour restrictions on learning opportunities in the intensive care unit. J Grad Med Educ. 2015;7(1):48-52. https://doi.org/10.4300/JGMED-14-00180.1

9. Elmariah $\mathrm{H}$, Thomas S, Boggan JC, Zaas A, Bae J. The burden of burnout: an assessment of burnout among Internal Medicine residents after the 2011 duty hour changes. Am J Med Qual. 2017;32(2):156-162. https://doi.org/10.1177/1062860615625802

10. Ripp JA, Bellini L, Fallar R, Bazari H, Katz JT, Korenstein D. The impact of duty hours restrictions on job burnout in internal medicine residents: a three-institution comparison study. Acad Med. 2015;90(4):494-499. https://doi.org/10.1097/ACM.0000000000000641

11. Desai SV, Feldman L, Brown L, et al. Effect of the 2011 vs 2003 duty hour regulation-compliant models on sleep duration, trainee education, and continuity of patient care among internal medicine house staff: a randomized trial. JAMA Intern Med. 2013;173(8):649-655. https://doi.org/10.1001/jamainternmed.2013.2973

12. Sen S, Kranzler HR, Didwania AK, et al. Effects of the 2011 duty hour reforms on interns and their patients: a prospective longitudinal cohort study. JAMA Intern Med. 2013;173(8):657-662. https://doi.org/10.1001 /jamainternmed.2013.351

13. Drolet BC, Christopher DA, Fischer SA. Residents' response to duty-hour regulations-a follow-up national survey. N Engl J Med. 2012;366(24):e35. https://doi.org/10.1056/NEJMp1202848 
14. Auger KA, Landrigan CP, Gonzalez del Rey JA, Sieplinga KR, Sucharew HJ, Simmons JM. Better rested, but more stressed? Evidence of the effects of resident work hour restrictions. Acad Pediatr. 2012;12(4):335-343. https://doi.org/10.1016/j.acap.2012.02.006

15. Auger KA, Jerardi KE, Sucharew HJ, Yau C, Unaka N, Simmons JM. Effects of the 2011 duty hour restrictions on resident education and learning from patient admissions. Hosp Pediatr. 2014;4(4):222-227. https://doi.org /10.1542/hpeds.2014-0004

16. Sandefur BJ, Shewmaker DM, Lohse CM, Rose SH, Colletti JE. Perceptions of the 2011 ACGME duty hour requirements among residents in all core programs at a large academic medical center. BMC Med Educ. 2017;17(1):199. https://doi.org/10.1186/s12909-017-1033-x

17. Lindeman BM, Sacks BC, Hirose K, Lipsett PA. Multifaceted longitudinal study of surgical resident education, quality of life, and patient care before and after July 2011. J Surg Educ. 2013;70(6):769-776. https://doi.org /10.1016/j.jsurg.2013.06.018

18. Schumacher DJ, Frintner MP, Jain A, Cull W. The 2011 ACGME standards: impact reported by graduating residents on the working and learning environment. Acad Pediatr. 2014;14(2):149-154. https://doi.org /10.1016/j.acap.2013.09.002

19. Krug MF, Golob AL, Wander PL, Wipf JE. Changes in resident well-being at one institution across a decade of progressive work hour limitations. Acad Med. 2017;92(10):1480-1484. https://doi.org/10.1097 /ACM.0000000000001675

20. Kreutzer L, Dahlke AR, Love R, et al. Exploring qualitative perspectives on surgical resident training, well-being, and patient care. J Am Coll Surg. 2017;224(2):149-159. https://doi.org/10.1016/j.jamcollsurg.2016.10.041

21. Nevin CR, Cherrington A, Roy B, et al. A qualitative assessment of internal medicine resident perceptions of graduate medical education following implementation of the 2011 ACGME duty hour standards. BMC Med Educ. 2014;14(1):84. https://doi.org/10.1186/1472-6920-14-84

Copyright $@ 2018$ by the Society of Teachers of Family Medicine 